Effects of Interviewer Familiarity and Supportiveness on Children's Recall Across Repeated Interviews

Sonja P. Brubacher

Centre of Investigative Interviewing, Griffith Criminology Institute, Griffith University

Debra A. Poole

(C) 2019, American Psychological Association. This paper is not the copy Central Michigan University of record and may not exactly replicate

Jason J. Dickinson the final, authoritative version of the article. Please do not copy or cite Montclair State University without authors' permission. The final article will be available, upon

David La Rooy and Zsofi Szojka publication, via its DOI: 10.1037/

School of Law, Royal Holloway University of London Ihb0000346

Martine B. Powell

Centre of Investigative Interviewing, Griffith Criminology Institute, Griffith University Author Note

Sonja Brubacher, Centre of Investigative Interviewing, Griffith Criminology Institute, Griffith University; Debra Poole, Department of Psychology, Central Michigan University; Jason Dickinson, Department of Psychology, Montclair State University; David La Rooy, School of Law, Royal Holloway University of London; Zsofi Szojka, School of Law, Royal Holloway University of London; Martine B. Powell, Centre of Investigative Interviewing, Griffith Criminology Institute, Griffith University.

This project was supported by an Early Career grant to the first author from the American Psychology-Law Society (APLS). Preliminary results were presented at the 2017 meeting of the APLS. The authors thank the children and schools who participated.

Address correspondence to Sonja P. Brubacher, Centre for Investigative Interviewing, Griffith Criminology Institute, Griffith University, 176 Messines Ridge Road, Mount Gravatt, 4122, QLD. E-mail: s.brubacher@griffith.edu.au 


\begin{abstract}
Objectives: Child witnesses often describe their experiences across multiple interviews. It is unknown whether talking with a familiar interviewer increases disclosures, however, or whether any benefits of a familiar interviewer could be achieved by ensuring that interviewers (regardless of familiarity) behave in socially supportive ways. This study tested the effects of interviewer familiarity and social support on children's reports of an adult's transgressions. Hypotheses: We predicted that familiarity and supportiveness would increase transgression reports at a second interview and that children who spoke with familiar, supportive interviewers would disclose the most transgressions. Method: Children $(N=160,5$ to 9 years $)$ participated in a science event involving six transgressions. Across two interviews, they spoke with the same trained university student interviewer or different interviewers, and these interviewers engaged in supportive or neutral behaviors. Interviews were coded for overall information reported, number of transgressions, and confabulations. Results: There were no effects of support in the first interview or on total details reported in either interview. Children reported more transgressions to supportive than neutral interviewers in the second interview $(I R R=1.19)$, even during openended prompting $(\mathrm{IRR}=1.26)$, and they omitted fewer transgressions that had been reported in the first interview $(I R R=0.69)$. Confabulations were infrequent. There were no condition differences in the total number of confabulations reported across interviews, but these errors occurred more often in the second interview in the supportive condition. Conclusions: Interviewer support may play a greater role than familiarity in facilitating children's testimony.
\end{abstract}

Keywords: repeated interviewing, interviewer support, interviewer familiarity, children, free recall 
Public Significance Statement: Children gave more complete and consistent reports of adult wrongdoing in response to open-ended questions when interviewers used a supportive (versus neutral) interviewing style across two interviews. The identity of the interviewer (same or different) had little impact on their accounts. Although further work is needed, these findings suggest that organizations should focus their efforts on ensuring that all interviewers are trained in best-practice interviewing, including the provision of social support. When a second interview is needed, using a different but highly trained interviewer may not be problematic. 
Effects of Interviewer Familiarity and Supportiveness on Children's Recall Across Repeated Interviews

Children who are alleged victims or witnesses of crimes often participate in multiple interviews about the matters under investigation (e.g., Malloy, Lyon, \& Quas, 2007). Concerns about repeated interviews have focused on the emotional toll on children (Connell, 2009), the potential for misleading influences to contaminate their testimonies between interviews (Ceci \& Bruck, 1995), and the negative and cumulative effects of poor questioning on the reliability of their accounts (Cronch, Viljoen, \& Hansen, 2006; Leichtman \& Ceci, 1995). As the quality of investigative interviews gradually improved, however, researchers and practitioners began to recognize the benefits of repeated interviews when professionals follow best-practice guidelines (Faller, Cordisco-Steele, \& Nelson-Gardell, 2010; Goodman \& Quas, 2008; La Rooy, Katz, Malloy, \& Lamb, 2010). Today, training programs that include instruction on conducting repeated interviews recommend many of the best practices originally developed for singlesession interviews (Newlin et al., 2015), including interview recording, favoring open-ended prompts, and avoiding suggestive and leading questions (see Lytle, Dickinson, \& Poole, 2019).

There are several potential benefits to interviewing children on more than one occasion. Some child victims may be reluctant to share their experiences due to fears about the consequences of disclosing (Malloy, Brubacher, \& Lamb, 2011), whereas others who provided incomplete and unconvincing accounts may benefit from another opportunity to discuss their experiences (McElvaney, 2015). Regardless of the reason for additional interviews, under nonsuggestive conditions repeated attempts at retrieval can strengthen memory traces, thereby preserving memories that children may be asked to retrieve weeks or even years later (Fivush, Sales, Goldberg, Bahrick, \& Parker, 2004; Pipe, Sutherland, Webster, Jones, \& La Rooy, 2004). 
Repeated retrieval also fosters reminiscence, which is the recall of new information in a subsequent interview (La Rooy et al., 2010).

Despite mounting evidence that repeated interviews can benefit children's testimony, there is insufficient research to guide practice. The current study addressed a frequently-posed question from professionals who interview children: Should agencies and advocacy centers use the same interviewer or a different interviewer across sessions? On the one hand, the same interviewer provides additional opportunities to strengthen children's trust by building greater rapport (Ahern, Sadler, Lamb, \& Gariglietti, 2017; La Rooy et al., 2010). If developing a relationship with a particular interviewer is key to increasing truthful disclosures, then consistent interviewers should be beneficial. On the other hand, children might report more information over time due to reminiscence (La Rooy et al., 2010) or because personal stories become easier to share. If this is the case, then the identity of the second interviewer could be irrelevant. Still another possibility is that the level of interviewer support enhances or attenuates any potential benefits of interviewer familiarity. It is possible, for example, that the emotional benefits from a familiar interviewer are greater when interviewers act supportively; alternatively, it may not matter who does the questioning as long as interviewers display supportive behaviors.

Understanding the relationship between interviewer familiarity, interviewer supportiveness, and children's testimony has important implications for jurisdictions that conduct repeated interviews because scheduling the same interviewer across sessions poses substantial logistical and financial challenges (e.g., children are sometimes interviewed by different agencies, there is significant workforce turnover in the child protection field). If interviewer familiarity does not yield clear benefits, however, then agencies can forego the assignment of specific interviewers to individual cases and focus on supportive interviewing 
strategies. Unfortunately, existing evidence on the benefits of familiar and supportive interviewers lacks the consensus needed to identify the optimal conditions for multiple interviews.

\section{Interviewer Familiarity}

The few studies that systematically manipulated interviewer identity showed mixed results. Having a familiar interviewer for a second interview did not impact the number of event details that one sample of 5-year-olds, 7-year-olds, and adults freely recalled, but there were some limited benefits during recognition questions: 7-year-olds who had experienced an unbiased first interview, and adults who had experienced a misleading first interview, showed higher correct recognition rates in the familiar condition (Bjorklund et al., 2000). In another repeated-interview study, 5-year-olds provided fewer correct details to a familiar interviewer during free recall. However, familiarity benefitted the 3-year-olds by increasing accuracy during direct questioning, and both age groups were more accurate in the face of misleading questions when talking with a familiar interviewer (Quas \& Schaaf, 2002). These findings suggest that familiarity may not benefit free recall but sometimes helps children resist the social pressures inherent in more directive questioning.

Children's parents served as the familiar interviewers in a few studies. For example, Fivush, Hamond, Harsch, Singer, and Wolf (1991) assigned 2-year-old children (30 to 35 months) to one of three conditions that consisted of two interviews conducted six weeks apart: both by the children's mothers, both by a stranger (a female researcher), or a first interview by the mother followed by another by a stranger. Children reported the most information when interviewed twice by the stranger and the least when interviewed twice by their mothers. But the authors noted that mothers, who also had experienced the events in question and were thus not 
naïve, asked more specific questions than did the researcher interviewer. Most relevant to the current study, children were more consistent in the same-interviewer conditions and reported a greater number of new details to an unfamiliar second interviewer. Using a similar design, Jackson and Crockenberg (1998) compared single interviews conducted by parents or strangers (another child's parent) who delivered either misleading or non-misleading questions to 4-year old female children. In general, the children were less likely to correct strangers and provided more information to familiar parent interviewers. Unfortunately, despite the use of standardized questions, parents asked their children for more elaboration than did strangers. These findings illustrate that research contrasting parent versus non-parent interviewers is informative but limited in its ability to address the effects of interviewer familiarity because parents have effects on children's reporting tendencies that go beyond simply being familiar (Lawson, RodriguezSteen, \& London, 2018).

It is likely that the effects of interviewer familiarity depend on age-related cognitive changes, such as children's capacity to reason about what others are thinking (Carpendale \& Lewis, 2004). Because interviews are social interactions, questioning by the same interviewer may prompt a socially aware interviewee to provide new information and leave out information that has already been reported (thereby producing greater report consistency across unfamiliar interviewers). Between the ages of 3.5 and 5.5 years, typically-developing children begin to make a distinction between knowledgeable and naïve interviewers (Welch-Ross, 1999), and these conditions can be likened to familiar versus unfamiliar interviewers. Whether shifts occur in children's reactions to a familiar interviewer around 5 years is unclear, however, due the rarity of familiarity studies that included older children.

In sum, the effects of interviewer familiarity on children's testimony are unclear. Past 
studies used a wide range of research designs, conclusions were inconsistent, and interviewer identity was sometimes confounded with the types of questions asked (e.g., Fivush et al., 1991) or the inherent familiarity of the interviewer (e.g., comparing mother with stranger interviewers, e.g., Goodman, Sharma, Thomas, \& Considine, 1995; Jackson \& Crockenberg, 1998).

\section{Interviewer Support}

Interviewer support refers to various content-neutral strategies that help children feel safe and cared for during interviews, including smiling, nodding, making frequent eye contact, using the child's name, and adopting a relaxed and open posture (see Bottoms, Quas, \& Davis, 2007, for review). In contrast to interviewer familiarity, the effects of interviewer support on children's testimony are more conclusive, though gaps remain (Saywitz, Wells, Larson, \& Hobbs, 2019). Overall, lab-based research has found that children interviewed by supportive adults are more accurate when faced with suggestive and nonsuggestive specific questions (Almerigogna, Ost, Bull, \& Akehurst, 2007; Bottoms et al., 2007; but see Imhoff \& Baker-Ward, 1999). However, whether supportiveness would drive differences in reporting of accurate information in nonleading interviews is largely untested because the free recall phases in prior experimental studies were short, usually including between one to three prompts (e.g., Carter, Bottoms, \& Levine, 1996; Davis \& Bottoms, 2002; Quas \& Lench, 2007; Quas, Wallin, Pappini, Lench, \& Scullin, 2005).

In field studies of interviews with alleged victims, high levels of support have been associated with richer and more forensically-relevant accounts, less reluctance (e.g., Hershkowitz, 2009; Hershkowitz, Lamb, Katz, \& Malloy, 2015; Hershkowitz, Orbach, Lamb, Sternberg, \& Horowitz, 2006), and more rapid disclosure (Ahern, Hershkowitz, Lamb, \& Blasbalg, \& Karni-Visel, 2018). Although experimental paradigms have included stressful or 
negatively-valenced events, no studies directly testing interviewer supportiveness have asked children to conceal adult wrongdoing; therefore, the impact of supportive interviewing on disclosures, under conditions where ground truth is available, is unknown. Given that supportive interviewing reduces anxiety/arousal (Davis \& Bottoms, 2002; Quas, Bauer, \& Boyce, 2004; Quas \& Lench, 2007), it is reasonable to predict that supportive interviewers would obtain more complete disclosures than would neutral or non-supportive interviewers.

\section{The Current Study}

To advance practice guidelines for multiple interviews, we manipulated the familiarity of the interviewer and the level of interviewer support across two interviews with extended free recall phases. The effects of familiarity and support on disclosure reports individually are unclear, and studies have not explored the joint influence of these interview characteristics. In order to assess children's reports of adult wrongdoing, the to-be-remembered event contained six transgressions that formed a rich, cohesive sequence in which each transmission relied on commission of the previous one. The purpose of this design was twofold: (a) we wanted to increase the potential variability in how much wrongdoing children could report, and (b) we aimed to mimic, on a small and ethical scale, the situation in which an offender grooms a child for a more serious transgression by progressively increasing the severity of wrongdoing (Craven, Brown, \& Gilchrist, 2006).

We centered our predictions on children's reports of transgressions, rather than total event details, due to the relatively unique open-ended nature of our interviews and because effects in free recall data have typically been weak. Although findings have been somewhat mixed, prior literature led us to expect that familiarity and supportiveness would both drive increased reporting of transgressions at the second interview (Bjorklund et al., 2000; Saywitz et 
al., 2019). We further expected that children interviewed by a familiar, supportive interviewer would disclose more transgressions from the target event than children interviewed in the other condition combinations.

\section{Method}

\section{Participants}

Deakin university's human research ethics committee and the local school board granted approval for the research, with principals providing organizational consent from each school. Schools received \$50 AUD for every classroom with participating children.

The children attended four elementary schools in a large Australian city. Parents signed informed consent forms, and children assented to participation. Among 194 children who returned signed consent forms, 160 fully participated. The remaining 34 children either missed part of the event session ( $n=1$ ), Interview 1 (and thus were never interviewed, $n=20$ ), or Interview $2(n=8)$; had language difficulties that precluded participating in the interview ( $n=$ 3); participated in a nonrecorded interview $(n=1)$; or were erroneously interviewed in both support conditions $(n=1)$. The final sample ranged from 5.19 to 9.55 years of age $($ mean age $=$ 7.24 years ( $S D=1.20$ years). (See Table 1 for the age and gender composition of each condition combination.)

\section{Materials and Procedure}

Event. The children experienced an adaptation of the Mr. Science-Germ Detective event (Dickinson \& Poole, 2017). Female research assistants collected pairs of children from their classrooms and escorted them to the "science room." Prior to meeting Mr. Science, the assistant verbally alerted the children to two rules for the session and directed their attention to a sign with images that depicted the rules. The rules were that Mr. Science should not touch the children's 
skin, purportedly to prevent germ transmission, and that no one should interact with equipment covered by a sheet. The children then met Mr. Science and began the session.

Over a 20-minute period, Mr. Science engaged the children in three main activities: learning about germ travel, learning about germ transfer, and proper hand washing. Interspersed between these activities, Mr. Science attempted to engage the children in six transgressions, each incrementally related to the previous one. For example, immediately after the germ travel activity, Mr. Science said, "I really want to know what is under that sheet. Do you want to know?" Regardless of children's responses, Mr. Science said, "Let's just take a tiny little peek," and removed the sheet to reveal a closed cabinet, exclaiming, "It looks like it must have such fun things inside! But we're not supposed to open it." They then left the sheet off the cabinet and returned to the second activity. The six transgressions the children actively or passively (by watching Mr. Science) participated in were (a) removing the sheet; (b) opening the cabinet to find the Top Secret Science Experiment box; (c) opening the box to remove the Energy Stick ${ }^{\text {TM }}$ and instructions; (d) holding hands with Mr. Science in order to form a circle (thereby completing a circuit); (e) activation of the Energy Stick ${ }^{\mathrm{TM}}$, which caused flashing lights and intriguing noises; and (f) hiding evidence by washing their hands after touching each other's skin "in order to remove germs." (The Energy Stick ${ }^{\mathrm{TM}}$ [www.stevespanglerscience.com] is a demonstration of electricity conduction.)

Mr. Science made up to two explicit attempts to incite children to hold his hands, but some children refused (42 refused, 104 complied, and the behavior of 14 children was unknown due to poor video angle). Known hand-holders were distributed similarly across conditions, with 25 in the unfamiliar and neutral condition, 25 in the familiar and neutral condition, 26 in the unfamiliar and supportive condition, and 28 in the familiar and supportive condition. When children refused 
to hold Mr. Science's hand, he showed them how to make it work by themselves. In some cases, one child of the pair held hands with Mr. Science while the other child watched. Four pairs of children (eight children) refused to touch the stick, so Mr. Science activated it alone.

After the hand-washing activity, Mr. Science returned all transgression-related materials to their original location and asked the children not to tell the people he works with at the university about the transgressions. For ethical reasons, Mr. Science did not ask the children to keep the secret from other people (e.g., parents, teachers). (See section SI.A of the online supplementary material for the event script.)

Interviews. Interviewers (who were not present at event sessions) conducted interviews with individual children on two occasions: 3 to 4 days after the event $(M=3.40, S D=.49)$, and again 3 to 5 days after the first $(M=4.08, S D=.89)$. All second interviews occurred within 6 to 8 days of the event $(M=7.31, S D=.68)$. The female interviewers were seven undergraduate students and one graduate student, randomly assigned to children and interview conditions, who interviewed in all conditions.

Both interviews commenced with ground rules (Brubacher, Poole, \& Dickinson, 2015) and a brief practice narrative (Roberts, Brubacher, Powell, \& Price, 2011), after which interviewers introduced the topic by saying, "I work at the university, and I heard that somebody else from the university came to play Germ Detective with you a little while ago. Did you play Germ Detective?" After children said "yes" (all did), interviewers prompted them to "Tell me everything that happened that day at Germ Detective."

Interview 1 consisted of a free recall phase only (predominately open-ended questions such as "What else happened" and "Tell me more about [predisclosed detail]"). Interviewers questioned children until probing in this manner yielded no further information (i.e., children 
claimed to have reported all they could remember).

In Interview 2, after free recall was exhausted, interviewers asked children up to six additional focused questions about Mr. Science and wrongdoing. The first prompt was, "Tell me all about Mr. Science," followed by questions about whether someone had done something wrong during the event, what the rules were, whether rules had been broken, and finally—if the children had not identified the two rules - direct questions about the rules (e.g., "Was there a no touching rule?”). Interviewers could ask two follow-up questions (i.e., "Tell me more about...”) per focused question.

Interview manipulations. We assigned children pseudorandomly to familiarity and support conditions (i.e., with restrictions to maintain balance across ages and genders). Depending on the child's familiarity condition, the interviewer was the same or different from the first to the second interview. Interviewers conducting second interviews did not review what children had said in the first.

For each child, first and second interviews were conducted in the same support condition (supportive or neutral). Interviewers displayed supportiveness using elements from previous research (Saywitz et al., 2019). The high support condition included encouragement for effort, using the child's name, forward lean, open body posture, and frequent eye contact and smiles. In the neutral support condition, interviewers tried to avoid these behaviors by maintaining a kind but cool, professional, and distanced air. Aside from these manipulations, interviewers strived to conduct sessions as similarly as possible (i.e., number and type of questions asked). Periodically during data collection, the first author viewed interviews at random to verify continued adherence to interview conditions. Further, a study on nonverbal behavior assessed differences in levels of expressivity, attention, and mutual coordination in a sub-sample of the children's first 
interviews ( $n=123$; Johnston, Brubacher, Powell, \& Fuller-Tyszkiewicz, 2019). For that study, two blind research assistants coded the sub-sample of interview videos with sound muted to minimize verbal clues to condition. Of the sample, $20 \%$ of interviews were double-coded for reliability (intraclass correlation coefficient $[\mathrm{ICC}]=.98$ ). At six pre-selected time points during the interview, interviewers' nonverbal behavior (averaged across measures of expressivity, attention, and mutual coordination) differed across supportive and neutral conditions, suggesting that interviewers behaved according to their assigned interview condition.

Interviewers did not give children a reason for the second interview unless children complained or otherwise indicated that they had been interviewed previously. In such cases, the second interviewer told the child that there had been problems with the recording of the first interview. As in Quas and Schaaf (2002), children rarely referred to their prior interview: Just five did so ( $3 \%$ of the sample), equally distributed across support condition but all in the familiar interviewer condition.

\section{Coding}

Research assistants and a professional transcriber transcribed the interviews. Coders recorded the number and types of questions interviewers used to ensure that interviewers had properly conducted the free recall phases. Indeed, these phases were predominantly open-ended in both interviews ( $\left.M_{1}=92 \%, S D_{1}=11 \%, M_{2}=95 \%, S D_{2}=9 \%\right)$.

Next, two student assistants read a random subset of 45 transcripts and compared these to the event script to identify potential target details. These tended to involve people, activities, and objects, and yielded 62 possible target details. Two different assistants, blind to the children's conditions, then coded interview transcripts for mention of the target details and each of the six transgressions. To be counted as a transgression, children had to be clear that the activity had 
happened: Coders did not count a transgression when children said that Mr. Science wanted to do something but without reporting that he actually had (e.g., "He wanted to look inside the box but we told him no"). There was one exception: Whenever children reported that Mr. Science tried to coax them to break rules, this was counted as a transgression even if the children themselves did not comply (e.g. "He tried to hold our hands" or "He said it would be ok to just take a peek under the sheet"). We considered these transgression reports because they documented explicit attempts to break one of the rules. In forensic interviews, attempted transgressions may nevertheless be of corroborative value (e.g., if a child reports that a suspect tried to share pornographic materials and the child did not want to look at them).

Transgression reports included explicit disclosures (e.g., "He told us to put our hands on [the energy stick] to light it up, so we did") and implicit disclosures (e.g., "I saw the flashing lights and sounds"). In other words, sometimes children's guilty knowledge indicated a transgression had taken place even though they did not report it outright as a transgression. Such information would nonetheless be relevant in a forensic interview.

Coded confabulations included any mention of something that did not happen during the activity, excluding minor detail errors (e.g., saying that the purple glitter was blue). Most of the children's confabulations pertained to activities they might do in school but did not do during the science activity (e.g., "We had a snack," "We played 'What time is it Mr. Wolf?"”) or extrapolations of the germ detective activity (e.g., "We had to make the light glow, which was his son's science project").

\section{Reliability}

Three teams coded the data. The first team, previously trained on an unrelated interview set, coded a random sample of $33 \%$ of interviews for number of interviewer prompts and 
question type. The ICC for the number of interviewer prompts was .99. Cohen's kappa for categorizing question types ranged from $.82-1.00$. The second team, trained with a random sample of ten transcripts, coded target details (maximum $=62$ per interview). A random selection of $20 \%$ of the remaining interviews provided double-coded data for computations of Cohen's kappas (whether each detail was mentioned or not); range $=.66-1.00$. A third team double-coded $100 \%$ of transcripts for confabulations and agreed on all identifications. The first team also double-coded all transcripts for transgression reports. Cohen's kappas for spotting individual transgressions in Interviews 1 and 2 were all greater than .94; ICCs for the derived transgression report variables, listed in Tables 2 and 3, were greater than .93.

\section{Results}

Unless otherwise noted, we used a generalized linear mixed model procedure for factorial analyses (Poisson distribution with a log link function for count variables) and report Type III tests of fixed effects. Means describing main effects of familiarity and support are unweighted.

The major purpose of Interview 1, which included only open-ended prompts, was to allow us to manipulate interviewer familiarity in Interview 2. Although all interviewers were unfamiliar to the children initially, we included the familiarity condition in subsequent 2 (familiarity: unfamiliar vs. familiar) by 2 (support: neutral vs. supportive) analyses of Interview 1 to confirm that procedures and children's performance were initially comparable for children who later experienced an unfamiliar versus familiar interviewer.

\section{Preliminary Analyses}

See sections SI.B and SI.C of the online supplementary material for details about preliminary analyses. Interview conditions were balanced for children's ages, the percentages of females versus males, the number of days between the event and interviews, and the number of 
prompts interviewers delivered during open-ended questioning (see Table 1).

We compared mean ages (at time of the event) across conditions; all $p \mathrm{~s}>.54$. The sample was $48 \%$ female, and there were no significant gender disparities across levels of the familiarity or support conditions, Fisher's exact tests, $p \mathrm{~s}>.53$.

Interview 1 occurred 3 or 4 days after the event ( $M=3.39$ days), with similar delays across levels of the familiarity and support conditions (see Table 1), Fisher's exact tests, $p \mathrm{~s}>.41$. Interview 2 occurred 3 to 5 days later $(M=4.08)$. There were no significant condition differences for this delay or the delay between the event and Interview 2 (6 to 8 days, $M=7.31$ ), MannWhitney U tests, $p \mathrm{~s}>.42$.

Interviewers delivered varying numbers of prompts during open-ended prompting, ranging from 5 to 35 prompts in Interview $1(M=13.64, S D=4.02)$ and from 3 to 21 prompts in Interview $2(M=11.29, S D=3.00)$. Analyses of prompt number within each interview did not find significant main effects of age or interactions involving age, even with the 3-way interaction omitted from the models, $p \mathrm{~s}>.10$. Thus, interviewers tailored prompting for individual children but offered similar opportunities to respond across ages and experimental conditions. However, relationships between the number of prompts and event details were not significant (Interview 1, $r=-0.15, p=.07$; Interview $2, r=-.08, p=.35)$, and this was true even with age controlled $(p \mathrm{~s}=$ .18 and .84 , respectively).

We analyzed the amount of event information reported during free recall in Interviews 1 and 2 with a series of 2 (familiarity) by 2 (support) factorial analysis after first including age to explore for interactions involving age. Age was a continuous variable in these analyses, which we conducted with and without the 3-way interaction. As expected, with increasing age the children reported more details in Interview $1, F(1,153)=81.67, p<.001$, estimated incidence 
rate ratio $(\mathrm{IRR})=1.14,95 \% \mathrm{CI}[1.11,1.17]$ and in Interview $2, F(1,153)=47.23, p<.001$, IRR $=1.21,95 \% \mathrm{CI}[1.15,1.28]$ (negative binomial distribution). Age was not significantly associated with the number of transgression reports in Interview 1, when prompting was only open-ended, $F(1,153)=3.61, p=.06$, or in Interview $2, F(1,153)=3.78, p=.05$. Because there were no significant interactions involving age, and age was balanced across conditions, we omitted age from subsequent analyses.

\section{Event Reports}

Interview 1. Factorial 2 (familiarity) by 2 (support) analyses of the number of event details reported, and the number of transgressions reported, revealed no significant effects in Interview 1 (see Table 2 for means and inferential statistics). Only 9 children (6\% of the sample, all males) confabulated in Interview 1, and each of these children offered only one confabulation: 6 in the neutral condition and 3 in the supportive condition, Fisher's exact test, $p=$ .32 .

Interview 2. See Table 2 for means and inferential statistics. As in Interview 1, condition assignment had no significant impact on the number of target event details the children reported during open-ended prompting (negative binomial distribution). Contrary to expectation, interviewer familiarity did not significantly impact transgression reports in the second interview, nor did interviewer familiarity interact with support. As predicted, however, supportively interviewed children reported more transgressions than neutrally interviewed children. This was true in response to all questions and when only free recall questions were considered (before interviewers delivered focused questions). Supportive interviewing did not eliminate reluctance to report transgressions, however: $12 \%$ of children in the supportive and $9 \%$ in the neutral condition reported no or only 1 transgression in Interview 2. Rather, supportive interviewing 
mostly increased transgression reports among children who were already disclosing. For example, the percentages of children in the neutral condition who reported 4, 5 , and 6 disclosures were $26 \%, 18 \%$, and $4 \%$, respectively, but these percentages shifted to $32 \%, 23 \%$, and $17 \%$ in the supportive condition.

But supportive interviewing did have a cost. Only 1 (male) child in the neutral condition offered a confabulation in Interview 2 ( $1 \%$ of the sample), compared to 8 children in the supportive condition ( $10 \%$ of the sample, 2 males and 6 females), Fisher's exact test, $p=.034$. All mentioned only a single confabulation. None of these nine children had confabulated in Interview 1, and the condition difference across Interviews 1 and 2 (total: 7 in the neutral condition vs. 11 in the supportive condition) was not significant, $p=.46$. Confabulations were not related to interviewer familiarity in Interview 2, $p=.74$.

Although there were few confabulations in the current study, a single confabulation can have serious consequences in a forensic interview. As such, we conducted post hoc coding of the types of confabulations across the two interviews. There were three types of confabulations: made-up information about Mr. Science $(n=4,2$ in each condition; e.g., "I think his name is Nathan or something"), intrusions of typical children's activities into the event ( $n=5,3$ in the neutral and 2 in the supportive condition; e.g., "We got to play tiggy [tag] and hide and seek"), and expansions on the germ theme ( $n=9,2$ in the neutral and 7 in the supportive condition; e.g., "We looked for germs all around the school" when they only searched in the classroom). The type of error was not significantly associated with support condition, Freeman-Halton extension of Fisher's exact test, $p=.38$.

\section{Consistency Across Interviews}

Fine-grained analyses explored how familiarity and support influenced the consistency of 
transgression reports across Interviews 1 and 2. Table 3 parses transgression reports into reports mentioned only in Interview 1, reports mentioned only in Interview 2 (reminiscence), and reports mentioned in both interviews (repeated reports). Because there were no significant interactions of familiarity and supportiveness in factorial analyses of these variables, we report only main effects. (See section SI.D of the online supplementary material for details.)

Supportively interviewed children were less likely than neutrally interviewed children to describe a transgression only in Interview 1, indicating that supportive interviewing helped children maintain consistency by reducing the tendency to omit information they had already discussed. Supportive interviewing elicited descriptively more new disclosures in Interview 2 compared to neutral interviewing, but this difference was not significant. The number of disclosures reported in both interviews did not differ significantly across support conditions,.

Interviewer familiarity did not significantly influence the number of reports that appeared only in Interview 1, or the number of repeated reports. The children were less likely to report new transgressions to a familiar than unfamiliar interviewer in Interview 2, however. To recap, supportive interviewing increased consistency by reducing the number of transgressions reported only in Interview 1, whereas unfamiliar interviewers increased new reports (reminiscence) in Interview 2.

\section{Discussion}

This study examined the impact of interviewer familiarity and supportiveness on the quality of children's reports across multiple interviews characterized by a predominantly openended questioning style. Contrary to our prediction, familiar interviewers did not elicit more reports of transgressions in Interview 2 than unfamiliar interviewers did. Also, familiar interviewers elicited fewer new reports, perhaps because their presence cued the previous 
conversation. Supportive behaviors, however, encouraged transgression reports among children interviewed a second time. Notably, there was a facilitative effect of interviewer support even before interviewers asked focused questions, suggesting that support may reduce the need for specific questions to elicit additional disclosures from children. We also found that supportive interviewing encouraged consistency: Compared to children interviewed neutrally, children questioned by a supportive interviewer were less likely to omit a previously reported transgression from their second interview. This outcome is relevant to professionals who prepare children to repeat their accounts in court (Saywitz, Goodman, \& Lyon, 2002) and suggests that the effects of questioner support beyond the forensic interview must be considered in research and practice. For example, a lack of support may be one of several contributors to the inconsistencies that arise during cross-examination with children (e.g., see Zajac, O’Neill, \& Hayne, 2012)

It is unclear what phenomenon drove the increase in transgression reports when children experienced supportive versus neutral interviewing in Interview 2. This advantage could be due to more extensive memory searching, which fosters retrieval of previously-reported as well as new event components. Social support is believed to make children feel more comfortable, which, in turn, allows them to engage in more careful memory retrieval (Bottoms et al., 2007). If supportive interviewing at the second interview solely affected reminiscence, however, one would expect to observe an overall increase in new target event details (e.g., La Rooy, Pipe, \& Murray, 2005) instead of a concentrated effect on transgression reports. Alternatively, it could be due to a reduction in motivational barriers to disclosing (i.e., reluctance) when children had the opportunity to share their experience a second time. Much of the supportiveness literature suggests that non-contingent support should decrease barriers to reporting of sensitive 
information (Bottoms et al., 2007). Finally, it is plausible that both mechanisms operate together.

There are several possibilities as to why an effect of interviewer support was absent in Interview 1. A recent systematic review and meta-analysis of 13 experimental studies and 2 exceptional quasi-experimental field studies also concluded that there are generally few effects of interviewer support in free recall phases. There was some evidence, however, that supportiveness effects would be stronger with particularly anxious children; when contrasted against explicitly unsupportive behaviors like disapproval, frustration, and contradiction; and at longer delays than typically employed in analog studies (Saywitz et al., 2019). By using neutral rather than non-supportive interviewers in the current study, and avoiding specific and suggestive questions, we therefore stacked the deck against finding any effects of supportiveness. But this design was purposeful: We argue that our manipulation increased ecologically validity because few interviewers today are overtly unsupportive (see Lewy, Cyr, \& Dion, 2015, and Hershkowitz et al., 2006). This design decision likely made it difficult to detect any effects of supportiveness only days after the event, when memory traces were strong and children in both conditions averaged several transgression reports. Because support is believed to encourage more effective memory searches (Bottoms et al., 2007), perhaps its effects are evident only when memory has weakened somewhat.

The benefit of interviewer support did come at a cost: In the second interview, supportive interviewers elicited more confabulations than did neutral interviewers (but across both interviews, there were no differences). These confabulations were primarily intrusions of typical activities and elaborations on the germ theme, rather than fantastic details, and none were concerning. We speculate that comfort and sociability increased for some children when a friendly person interviewed them for the second time. This is consistent with the finding that 3- 
to 7-year olds who were temperamentally more sociable produced higher levels of inaccurate details when interviewed by forensic interviewers about a magic show, compared to less sociable peers (Gilstrap \& Papierno, 2004). Alternatively, this could be an unstable finding because there was not a significant effect of supportiveness on the number of confabulations elicited across interviews. Future research is needed to assess the stability of - and underlying contributors toelevated confabulation rates in Interview 2. Further, this effect should be studied under conditions where children who have not experienced transgressions are questioned by interviewers who believe they have.

\section{Limitations, Caveats, and Future Directions}

The current research was an analog study, which has the benefits of experimental control and ground truth (interview coders can check children's reports against what really happened). Yet, such studies come with a set of limitations. First, we maintained control by using trained university students as interviewers, and they were required to follow protocols that did not permit the discretion typically afforded professional interviewers. Therefore, our findings should be replicated with forensic interviewers. Second, transgressions were of a nature that would be ethical for research. Although children's narratives suggested that they took the rules seriously, it is likely that they were less reluctant to disclose than are typical children in abuse investigations. Indeed, only 12 children (8\%; six per supportiveness condition) disclosed no transgressions in Interview 1, with 5 (3\%) failing to disclose at the second. As such, the effect of interview support in the present study applied to children who were already disclosing. Future work should use a paradigm that introduces more variability into children's disclosures so that the effects of support and familiarity can be tested on children who do not initially disclose. Relatedly, we do not know the extent to which children may have discussed the event (or interviews) with others. This 
limitation is typical of memory studies with children participating in schools. Due to decreased reluctance and possible cross talk, children in the present study may have disclosed adult wrongdoing at a higher rate than would children in forensic interviews, but we anticipate that the pattern of behavior across conditions would be similar.

A few design features may have limited our ability to find effects. While our sample size should have been sufficient to detect less than a medium effect size for main effects, the interactions may have been underpowered. This could explain why the predicted interaction between support and familiarity was not supported. Also, interviewers did not give children a reason for the second interview unless the child complained, and few did. We made this design decision to ensure as much similarity between familiarity conditions as possible (so as not to confound familiarity with cueing the prior interview), but it is possible that children would be more forthcoming with a familiar interviewer who explained the need for more information in the second interview. Future research should disentangle interviewer familiarity from the effect of cueing the prior interview by including conditions where familiar interviewers either do or do not remind children of their earlier interview.

Due to interviews being relatively brief, some children in the familiar interviewer condition may not have recognized that the same person was interviewing them. This situation, if it occurred often enough, also would have masked effects of a familiar interviewer. Future research should determine whether children recognize familiar interviewers. Relatedly, we did not ask the children about their perceptions of the interviewers. Although interviewers behaved in accordance with condition assignments, whether children perceived them to be supportive or neutral is unknown, and some manipulations of interviewer support (e.g., open versus closed body posture) may not be salient to children (Almerigogna, Ost, Akehurst, \& Fluck, 2008). To 
our knowledge, none of the experimental research testing familiarity has included a final set of questions prompting children for perceptions of their interviewers, but we suggest these queries be included because they could provide important insights into children's perceptions of interviewers when they encounter them more than once. Indeed, Quas and colleagues (2004) solicited 4- to 6-year olds' impressions of high- versus low-support interviewers with stick-figure facial expressions, and found that children in the high-support condition picked significantly happier faces.

A caveat rather than a limitation per se relates to the design of our interviews. There is a difference between repeated interviews and extended interviews (see Carnes, Nelson-Gardell, Wilson, \& Orgassa, 2001, for an overview of the extended evaluation model). In the present study, children were re-interviewed about the same topic because we were interested in studying reminiscence and there are numerous situations where children will give the same account repeatedly (such as when they first disclose to a social worker and then converse with the police or give testimony in court; La Rooy et al., 2010). In contrast to repeated interviews, extended interviews stretch a forensic interview across multiple sessions. Topics may be revisited if the information obtained was sparse or confusing, but the goal is generally to progress through the allegation or allegations rather than revisit the same information. Extended interviews are frequently planned when interviewers have reason to suspect that victims will be highly reluctant. In these cases, the effects of interviewer familiarity might be significant, and this is an important question for future work. Indeed, Ahern and colleagues (2017) found that practitioners who interview child exploitation victims said they had to meet with victims many times (sometimes over a period of years) to establish trust because the victims had such a deep-rooted mistrust of authority figures. Investigation details were not discussed at these early sessions, 
however.

\section{Conclusion}

In sum, results from this study add to existing findings that supportive interviewing can facilitate children's reports, especially when combined with a second opportunity for retrieval under optimal interviewing conditions. Although more research is needed, these findings are good news for agencies that wish (or need) to conduct repeated interviews. Our results suggest that the identity of the interviewer is less critical than is high quality interviewer training, including practice in using social support. These findings, however, may not extend to situations where victims need multiple exposures to an interviewer before feeling comfortable enough to disclose. Ultimately, case features and investigative needs should drive decisions about who conducts a child's subsequent interview. 


\section{References}

Ahern, E. C., Hershkowitz, I., Lamb, M. E., Blasbalg, U., \& Karni-Visel, Y. (2018). Examining reluctance and emotional support in forensic interviews with child victims of substantiated physical abuse. Applied Developmental Science. Advance online publication. doi: $10.1080 / 10888691.2017 .1387057$

Ahern, E. C., Sadler, L. A., Lamb, M. E., \& Gariglietti, G. M. (2017). Practitioner perspectives on child sexual exploitation: Rapport building with young people. Journal of Child Sexual Abuse, 26, 78-91. doi: 10.1080/10538712.2016.1257529

Almerigogna, J., Ost, J., Akehurst, L., \& Fluck, M. (2008). How interviewers' nonverbal behaviors can affect children's perceptions and suggestibility. Journal of Experimental Child Psychology, 100, 17-39. doi: 10.1016/j.jecp.2008.01.006

Almerigogna, J., Ost, J., Bull, R., \& Akehurst, L. (2007). State of high anxiety: How nonsupportive interviewers can increase the suggestibility of child witnesses. Applied Cognitive Psychology, 21, 963-974. doi: 10.1002/acp.1311

Bjorklund, D. F., Cassel, W. S., Bjorklund, B. R., Brown, R. D., Park, C. L., Ernst, K., \& Owen, F. A. (2000). Social demand characteristics in children's and adults' eyewitness memory and suggestibility: The effect of different interviewers on free recall and recognition. Applied Cognitive Psychology, 14, 421-433. doi: 10.1002/10990720(200009)14:5<421::AID-ACP659>3.0.CO;2-4

Bottoms, B. E., Quas, J. A., \& Davis, S. L. (2007). The influence of interviewer-provided social support on children's suggestibility, memory, and disclosures. In M.-E. Pipe, M. E. Lamb, Y. Orbach, \& A.-C. Cederborg (Eds.), Child sexual abuse: Disclosure, delay, and denial (pp. 135-158). New York, NY: Taylor Francis. 
Brubacher, S. P., Poole, D. A., \& Dickinson, J. J. (2015). The use of ground rules in interviews with children: A synthesis and call for research. Developmental Review, 36, 15-33. doi: 10.1016/j.dr.2015.01.001

Carnes, C. N., Nelson-Gardell, D., Wilson, C., \& Orgassa, U. C. (2001). Extended forensic evaluation when sexual abuse is suspected: A multisite field study. Child Maltreatment, 6, $230-242$.

Carpendale, J. I., \& Lewis, C. (2004). Constructing an understanding of mind: The development of children's social understanding within social interaction. Behavioral and Brain Sciences, 27, 79-96. doi: 10.1017/S0140525X04000032

Carter, C. A., Bottoms, B. L., \& Levine, M. (1996). Linguistic and socioemotional influences on the accuracy of children's reports. Law and Human Behavior, 20, 335-358. doi: 10.1007/bf01499027

Ceci, S. J., \& Bruck, M. (1995). Jeopardy in the courtroom: A scientific analysis of children's testimony. Washington, DC: American Psychological Association.

Connell, M. (2009). The child advocacy center model. In K. Kuehnle \& M. Connell (Eds.), The evaluation of child sexual abuse allegations: A comprehensive guide to assessment and testimony (pp. 423-449). Hoboken, NJ: Wiley.

Craven, S., Brown, S. \& Gilchrist, E. (2006) Sexual grooming of children: Review of literature and theoretical considerations, Journal of Sexual Aggression, 12, 287-299. doi: $10.1080 / 13552600601069414$

Cronch, L. E., Viljoen, J. L., \& Hansen, D. J. (2006). Forensic interviewing in child sexual abuse cases: Current techniques and future directions. Aggression and Violent Behavior, 11, 195207. doi: 10.1016/j.avb.2005.07.009 
Davis, S. L., \& Bottoms, B. L. (2002). Effects of social support on children's eyewitness reports: A test of the underlying mechanism. Law and Human Behavior, 26, 185-215. doi: 10.1023/A:1014692009941

Dickinson, J. J., \& Poole, D. A. (2017). The influence of disclosure history and body diagrams on children's reports of inappropriate touching: Evidence from a new analog paradigm. Law and Human Behavior, 41, 1-12. doi: 10.1037/ lhb0000208

Faller, K. C., Cordisco-Steele, L., \& Nelson-Gardell, D. (2010). Allegations of sexual abuse of a child: What to do when a single forensic interview isn't enough. Journal of Child Sexual Abuse, 19, 572-589. doi: 10.1080/10538712.2010.511985

Fivush, R., Hamond, N. R., Harsch, N., Singer, N., \& Wolf, A. (1991). Content and consistency in young children's autobiographical recall. Discourse Processes, 14, 373-388. doi:10.1080/01638539109544791

Fivush, R., Sales, J. M., Goldberg, A., Bahrick, L., \& Parker, J. (2004). Weathering the storm: Children's long-term recall of Hurricane Andrew. Memory, 12, 104-118. doi: $10.1080 / 09658210244000397$

Gilstrap, L. L., \& Papierno, P. B. (2004). Is the cart pushing the horse? The effects of child characteristics on children's and adults' interview behaviours. Applied Cognitive Psychology, 18, 1059-1078. doi: 10.1002/acp.1072

Goodman, G. S., \& Quas, J. A. (2008). Repeated interviews and children's memory: It's more than just how many. Current Directions in Psychological Science, 17, 386-390. doi: 10.1111/j.1467-8721.2008.00611.x

Goodman, G. S., Sharma, A., Thomas, S. F., \& Considine, M. G. (1995). Mother knows best: Effects of relationship status and interviewer bias on children's memory. Journal of 
Experimental Child Psychology, 60, 195-228. . doi: 10.1006/jecp.1995.1038

Hershkowitz, I. (2009). Socioemotional factors in child sexual abuse investigations. Child Maltreatment, 14, 172-181. doi:10.1177/1077559508326224.

Hershkowitz, I., Lamb, M. E., Katz, \& Malloy, L. C. (2015). Does enhanced rapport-building alter the dynamics of investigative interviews with suspected victims of intra-familial abuse? Journal of Police and Criminal Psychology, 30, 6-14. doi: 10.1007/s11896-013-9136-8

Hershkowitz, I., Orbach, Y., Lamb, M. E., Sternberg, K. J., \& Horowitz, D. (2006). Dynamics of forensic interviews with suspected abuse victims who do not disclose abuse. Child Abuse \& Neglect, 30, 753-769. doi: 10.1016/j.chiabu.2005.10.016

Imhoff, M. C., \& Baker-Ward, L. (1999). Preschooler's suggestibility: Effects of developmentally appropriate language and interviewer supportiveness. Journal of Applied Developmental Psychology, 20, 407-429. doi: 10.1016/S0193-3973(99)00022-2

Jackson, S. L., \& Crockenberg, S. (1998). A comparison of suggestibility in 4-year-old girls in response to parental or stranger misinformation. Journal of Applied Developmental Psychology, 19, 527-542. doi: 10.1016/S0193-3973(99)80054-9

Johnston, V., Brubacher, S. P., Powell, M., \& Fuller-Tyszkiewicz, M. (2019). Patterns of nonverbal rapport behaviors across time in investigative interviews with children. Journal of Nonverbal Behavior. Advance online publication. doi: 10.1007/s10919-019-00306-1

La Rooy, D., Katz, C., Malloy, L. C., \& Lamb, M. E. (2010). Do we need to rethink guidance on repeated interviews? Psychology, Public Policy, and Law, 16, 373-392. doi: $10.1037 / \mathrm{a} 0019909$

La Rooy, D., Pipe, M. E., \& Murray, J. E. (2005). Reminiscence and hypermnesia in children's eyewitness memory. Journal of Experimental Child Psychology, 90, 235-254. doi: 
10.1016/j.jecp.2004.11.002

Lawson, M., Rodriguez-Steen, L., \& London, K. (2018). A systematic review of the reliability of children's event reports after discussing experiences with a naïve, knowledgeable, or misled parent. Developmental Review, 49, 62 - 79. doi: 10.1016/j.dr.2018.06.003

Leichtman, M. D., \& Ceci, S. J. (1995). The effects of stereotypes and suggestions on preschoolers' reports. Developmental Psychology, 31, 568-578. doi: 10.1037/00121649.31.4.568

Lewy, J., Cyr, M., \& Dion, J. (2015). Impact of interviewers' supportive comments and children's reluctance to cooperate during sexual abuse disclosure. Child Abuse \& Neglect, 43, 112122. doi: 10.1016/j.chiabu.2015.03.002

Lytle, N. E., Dickinson, J. J., \& Poole, D. A. (2019). Techniques for interviewing reluctant child witnesses. In J. J. Dickinson, M. R. McCauley, R. N. Carol, N. Schreiber, \& B. Schwartz (Eds.), Evidence-based investigative interviewing. London, England: Routledge.

Malloy, L. C., Brubacher, S. P., \& Lamb, M. E. (2011). Expected consequences of disclosure revealed in investigative interviews with suspected victims of child sexual abuse. Applied Developmental Science, 15, 8-19. doi: 10.1080/10888691.2011.538616

Malloy, L. C., Lyon, T. D., \& Quas, J. A. (2007). Filial dependency and recantation of child sexual abuse allegations. Journal of the American Academy of Child \& Adolescent Psychiatry, 46, 162-170. doi: 10.1097/01.chi.0000246067.77953.f7

McElvaney, R. (2015). Disclosure of child sexual abuse: Delays, non-disclosure and partial disclosure. What the research tells us and implications for practice. Child Abuse Review, 24, 159-169. doi: 10.1002/car.2280

Newlin, C., Steele, L. C., Chamberlin, A., Anderson, J., Kenniston, J., Russell, A., ... \& Vaughan- 
Eden, V. (2015). Child forensic interviewing: Best practices (pp. 1-20). U.S. Department of Justice, Office of Justice Programs, Office of Juvenile Justice and Delinquency Prevention. Retrieved from https://www.ojjdp.gov/publications/index.html.

Pipe, M. E., Sutherland, R., Webster, N., Jones, C., \& Rooy, D. L. (2004). Do early interviews affect children's long-term event recall? Applied Cognitive Psychology, 18, 823-839. doi: 10.1002/acp.1053

Quas, J. A., Bauer, A., \& Boyce, W. T. (2004). Physiological reactivity, social support, and memory in early childhood. Child Development, 75, 797-814. doi: 10.1111/j.14678624.2004.00707.x

Quas, J. A., \& Lench, H. C. (2007). Arousal at encoding, arousal at retrieval, interviewer support, and children's memory for a mild stressor. Applied Cognitive Psychology, 21, 289-305. doi: $10.1002 /$ acp. 1279

Quas, J. A., \& Schaaf, J. M. (2002). Children's memories of experienced and nonexperienced events following repeated interviews. Journal of Experimental Child Psychology, 83, 304338. doi:10.1016/S0022-0965(02)00150-9

Quas, J. A., Wallin, A., Papini, S., Lench, H., \& Scullin, M. (2005). Suggestibility, social context, and memory for a novel experience in young children. Journal of Experimental Child Psychology, 91, 315-341. doi: 10.1016/j.jecp.2005.03.008

Roberts, K. P., Brubacher, S. P., Powell, M. B., \& Price, H. L. (2011). Practice narratives. In M. E. Lamb, D. La Rooy, L. Malloy \& C. Katz (Eds.), Children's testimony: A handbook of psychological research and forensic practice (2d Ed., pp. 129-146). Chichester, UK: Wiley.

Saywitz, K.J., Goodman, G.S., \& Lyon, T.D. (2002). Interviewing children in and out of court: 
Current research and practice implications. In J. Myers, L. Berliner, J. Briere, C. T.

Hendrix, C. Jenny, \& T. Reid (Eds.), The APSAC handbook on child maltreatment (2d Ed., pp. 349-377). Thousand Oaks, CA: Sage.

Saywitz, K. J., Wells, C. R., Larson, R. P., \& Hobbs, S. D. (2019). Effects of interviewer support on children's memory and suggestibility: Systematic review and meta-analysis of experimental research. Trauma, Violence, \& Abuse, 20, 22-39. doi:

$10.1177 / 1524838016683457$

Welch-Ross, M. K. (1999). Interviewer knowledge and preschoolers' reasoning about knowledge states moderate suggestibility. Cognitive Development, 14, 423-442. doi:10.1016/S08852014(99)00013-1

Zajac, R., O'Neill, S., \& Hayne, H. (2012). Disorder in the courtroom? Child witnesses under cross-examination. Developmental Review, 32, 181-204. doi: 10.1016/j.dr.2012.06.006 


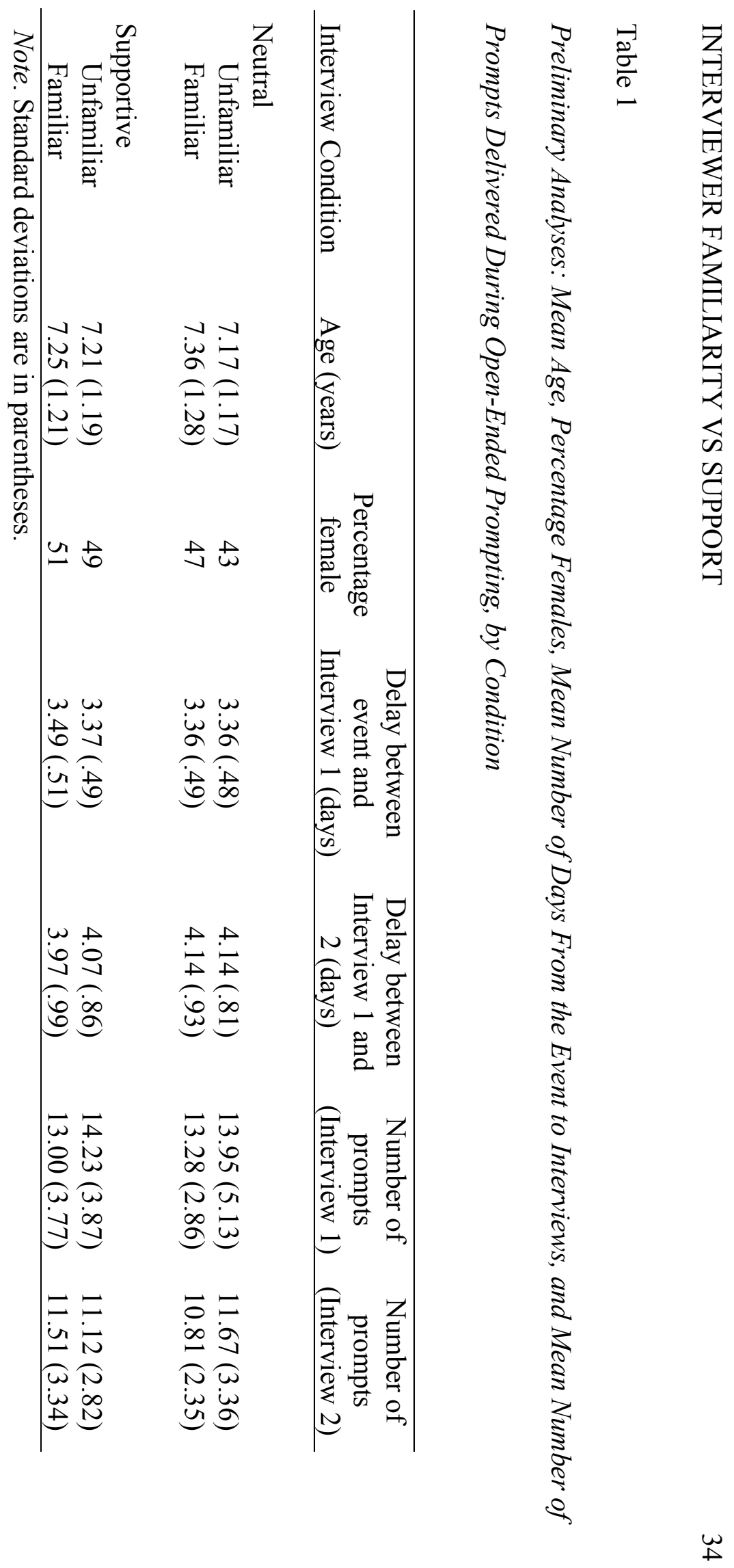




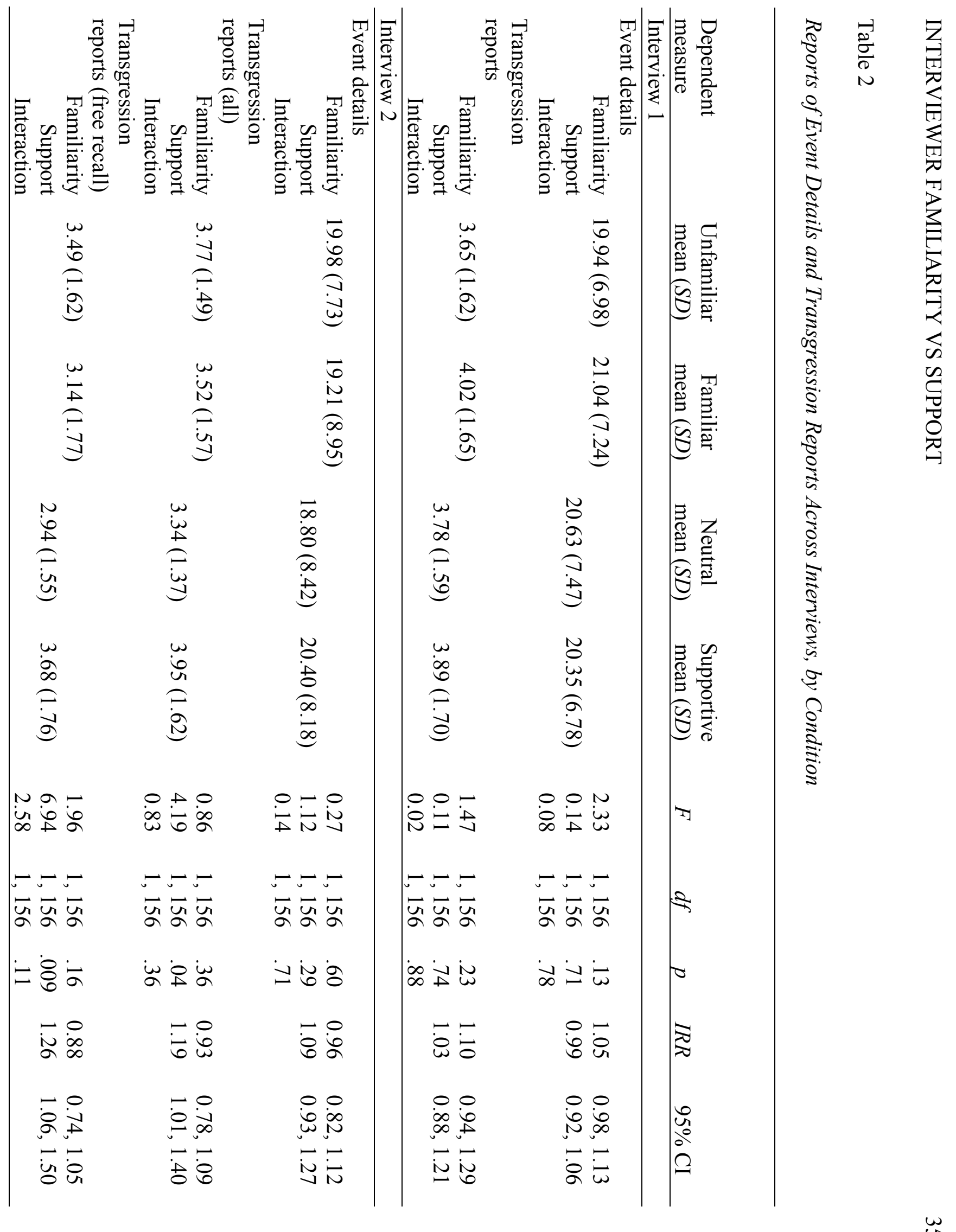



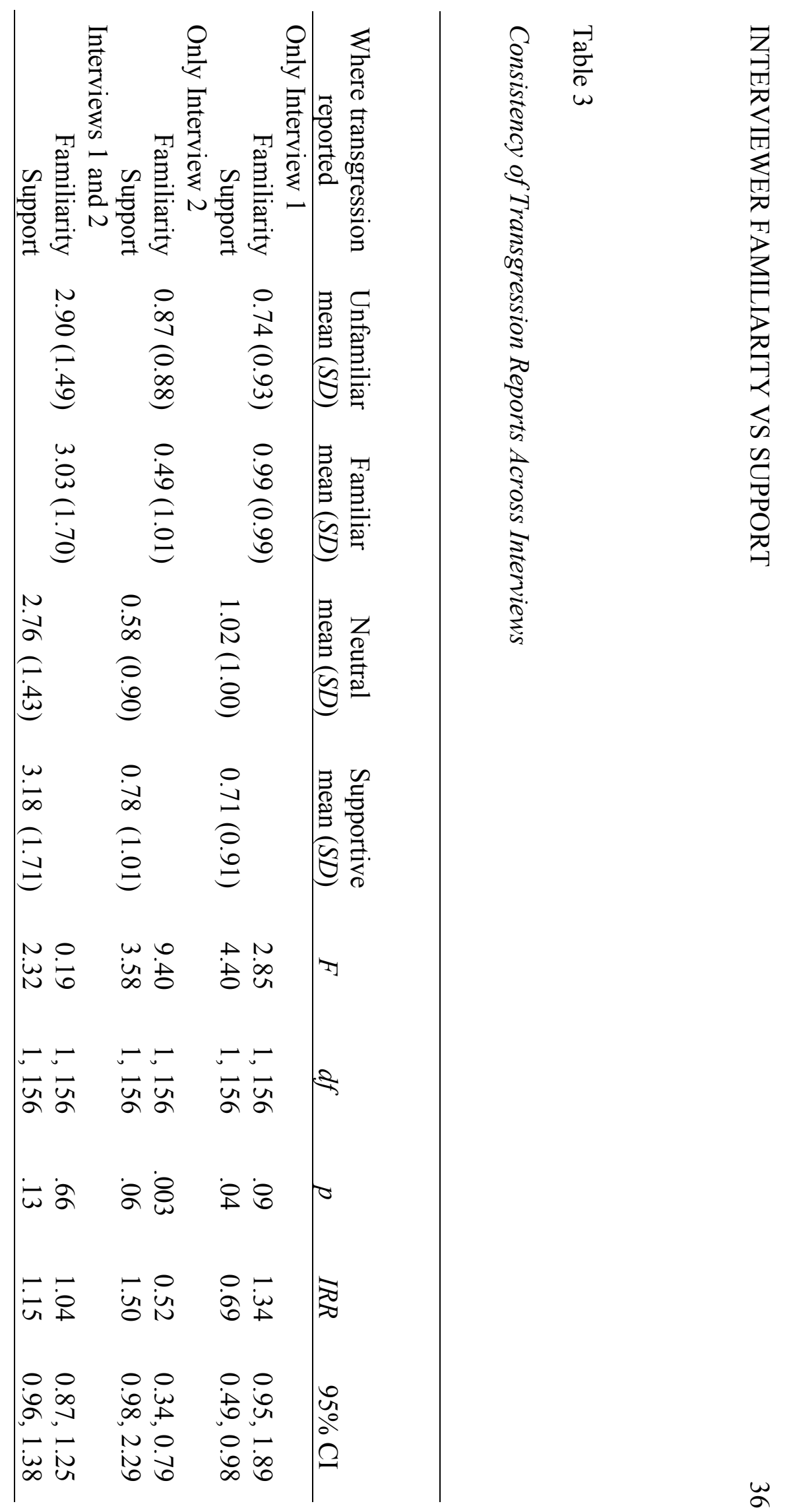